\title{
A memorial tribute to Tracy L. Faber, PhD
}

\author{
Ernest V. Garcia, PhD
}

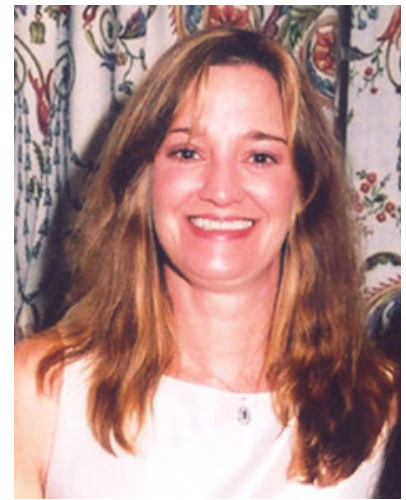

The field of nuclear cardiology lost an esteemed colleague and many of us lost a dear friend with the passing of Tracy Lynn Faber on March 24, 2012. A productive biomedical engineer and creative computer scientist Tracy died at home in Atlanta, suddenly and unexpectedly, at the age of 51 .

Tracy's most important contribution to our field was the development of software methods for the quantification and rendering of the three-dimensional (3D) myocardial perfusion images obtained from SPECT and PET studies. She further advanced these techniques by fusing together these 3D images of the heart muscle with the coronary tree distribution obtained from either noninvasive CT angiography or invasive coronary catheterization. These rendered hearts are not only diagnostically important but she made sure that they are also aesthetically beautiful, just like Tracy's own heart.

Tracy not only developed these sophisticated computer techniques but also responsible for determining their accuracy in animal models. These were very complicated experiments for which Tracy had to bring together a whole team of imaging and animal scientists.

From the Department of Radiology and Imaging Sciences, Emory University Hospital, Atlanta, GA.

Reprint requests: Ernest V. Garcia, PhD, Department of Radiology and Imaging Sciences, Emory University Hospital, 1364 Clifton Rd, NE, Atlanta, GA 30322; Ernest.Garcia@emory.edu.

J Nucl Cardiol 2012;19:395-6.

$1071-3581 / \$ 34.00$

Copyright (C) 2012 American Society of Nuclear Cardiology.

doi:10.1007/s12350-012-9568-z

Tracy's sensitivity and love for animals would often make these experiments difficult for her to perform. She would use pigs as her animal model and would give each pig an endearing name. It was not unusual to find her, after an experiment, sobbing in her office because her latest pig had to be killed. Nevertheless, she learned a great deal from this work. To this day, Tracy is recognized throughout the world as the most important scientific contributor to the development of these techniques for fusing anatomic images of the coronary tree with physiologic images of myocardial perfusion distributions.

Early in her career, Tracy's humble and unassuming ways hindered her from discussing the exact nature or her work or the importance of her scientific contributions. She was always competent and prepared but never comfortable in the limelight. In 1989, before coming to Atlanta, while working UT Southwestern in Dallas and in collaboration with Dr. Jim Corbett, Tracy had already developed the very first software method for measuring left ventricular ejection fraction from ECG-gated SPECT radionuclide ventriculograms. This team was also one of the first in the world to perform 3D motion and perfusion quantification from myocardial perfusion SPECT studies.

Originally from Apollo, PA, she graduated high school with a full scholarship to Case Western Reserve University, where she graduated with a Bachelor of Science in Biomedical Engineering (BSE) in 1982. She then enrolled at the University of Texas at Arlington where she received masters and $\mathrm{PhD}$ degrees in Biomedical Engineering. After graduating, she joined the faculty of the University of Texas, Southwestern as an assistant professor in the radiology and biomedical engineering departments. She joined Emory University in 1992 where she remained for the rest of her career. In 2009, she attained the rank of full professor in the department of radiology and imaging sciences with a second appointment in the joint Emory/Georgia Institute of Technology Biomedical Engineering Department.

Tracy's contributions to our Society were many. She was a member of ASNC since 2001 and served on numerous ASNC committees including the Ventricular Function Writing committee, Annual Program committees, the membership committee, and was a member of the editorial board of the Journal of Nuclear Cardiology. She often lectured at ASNC functions. 
Tracy was a scholar, mentor, and friend to many and will be remembered as an avid reader, a music and movie lover, a huge trivia buff, and an extremely loyal Steelers fan. Dr. Faber was a very devoted wife and stepmother. She is survived by her husband Denis Arra, step-daughters Meredith and Allison Arra, brother Doug
Faber, other relatives, numerous friends and her Emory nuclear cardiology research team: Russell Folks, David Cooke, Ji Chen, Nettie Sutton, Leah Verdes, Daya Manatunga, and Ernie Garcia. Thank you Tracy for 20 great years with our team. We will miss you. 